\title{
Epidemias, estado e sociedade: Minas Gerais na segunda metade do século XIX
}

\author{
Anny Jackeline Torres Silveira (*) \\ $\left.{ }^{*}\right)$ Universidade Federal de Minas Gerais (UFMG) - Brasil. anejack@terra.com.br
}

Dynamis

[0211-9536] 2011; $31(1): 41-63$
Fecha de recepción: 2 de febrero de 2010

Fecha de aceptación: 18 de diciembre de 2010

SUMÁRIO: 1.-Introdução. 2.-As epidemias na província de Minas Gerais. 3.—O Estado e a assistência em tempos de epidemia. 4.-Caridade e assistência em tempos de epidemia. 5.-Da compaixão à intolerância e de algumas práticas para se ver livre da ameaça epidêmica. 6.-Considerações.

RESUMO: Um dos aspectos que marcam as análises das doenças epidêmicas é a noção de crise: as epidemias são geralmente percebidas como eventos que fogem ao enquadramento engendrado pelos ordenamentos e práticas cotidianos, ultrapassando a experiência individual -o sofrimento, a ameaça da morte-, colocando em risco as próprias estruturas sociais, a ordem pública, as atividades econômicas, os valores morais. Entretanto, esses eventos também podem esclarecer sobre o modo como as sociedades organizam a assistência à saúde em tempos de normalidade, como a extensão e os limites da atuação das autoridades e o papel das populações no provimento de suas necessidades cotidianas. Este artigo aborda a organização dos serviços de assistência à saúde na província de Minas Gerais (Brasil) durante dois episódios epidêmicos — varíola (1873-1875) e o cólera (1855-1856) — identificando os problemas vivenciados pela população de Minas e as ações do poder público durante o curso dessas moléstias. Por outro lado, sugerimos que as dificuldades vivenciadas quando da instalação do cólera ou do recrudescimento da varíola, na verdade evidenciavam e aprofundavam as deficiências que caracterizavam o atendimento a saúde naquela sociedade, e que a mobilização social em torno dos doentes não se constituía uma novidade, uma vez que a intervenção do Estado no âmbito da saúde pública durante o período examinado era bastante reduzida, não prescindido da iniciativa e do apoio da sociedade civil.

PALAVRAS CHAVES: História da saúde, história do Brasil, epidemias, cólera, viruela.

KEY WORDS: History of public health, history of Brazil, epidemics, cholera, smallpox. 


\section{Introdução $(*)$}

As doenças epidêmicas têm se tornado um campo fértil para as análises históricas desde 1980. Tradição inaugurada ainda na década de sessenta pelos trabalhos de Louis Chevalier e Asa Briggs sobre as epidemias de cólera na Europa do século XIX ${ }^{1}$, os estudos dos eventos epidêmicos informados por uma perspectiva social expandiram-se de forma significativa, incorporando outras fronteiras geográficas e novas moléstias. Ainda que abordem doenças, lugares e tempos diferentes, um dos aspectos que marcam essas análises é a noção de crise: as epidemias são geralmente percebidas como eventos que fogem ao enquadramento engendrado pelos ordenamentos e práticas cotidianos da sociedade ${ }^{2}$, ultrapassando a experiência individual $-\mathrm{o}$ sofrimento, a ameaça da morte- colocando em risco as próprias estruturas sociais - a ordem pública, as atividades econômicas, os valores morais, os ritos religiosos- que cimentam e dão sentido à existência em comum.

Essa noção de crise associada ao evento epidêmico pode ser pensada em relação à rapidez e à intensidade com as quais a doença interfere na organização da vida social. A expansão do contágio muitas vezes impõe dificuldades de ordem material: um número crescente de doentes que ultrapassa os limites da assistência institucionalizada, que impõe investimento extra em cuidados, que mobiliza os sãos na cura dos enfermos, que interfere na execução das tarefas diárias, na reprodução da existência cotidiana. Muitas vezes essa expansão também se faz acompanhada pela dúvida, pela ausência de respostas positivas, pela impossibilidade do controle, pela incapacidade de explicar o mal e intervir sobre ele, pelo questionamento de saberes, práticas e crenças estabelecidas. E quanto mais intensa a manifestação da doença, mais dramáticos se tornam esses impactos na vida social.

Se as interferências produzidas por uma epidemia atingem as mais variadas dimensões da existência humana, o mesmo pode ser observado quando voltamos o olhar para as tentativas feitas por diferentes sociedades

$\left(^{*}\right)$ Esse texto é produto das pesquisas realizadas no através do projeto «A História da saúde na Província de Minas Gerais, século XIX», financiado pelo CNPq e FAPEMIG.

1. Briggs, Asa. Cholera and society in 19th century. Past and Present. 1961; 19: 76-96, e Chevalier, Luis. Le chólera: La première épidémie du XIXe siècle. Le Roche-sur-Yon: Impr. Centrale de I'Ouest; 1958.

2. Evans, Richard J. Epidemics and revolutions: cholera in nineteenth-century Europe. In: Ranger, Terence; Slack, Paul, eds. Epidemics and ideas: essays on the historical perception of pestilence. Cambridge: Cambridge University Press; 1992, p. 149-173. 
visando solucionar os impasses impostos pela doença. O enfrentamento da ameaça epidêmica envolve a mobilização não só dos recursos humanos e materiais na organização dos serviços de atendimento aos enfermos ou de respostas às suas conseqüências na vida cotidiana, mas também práticas culturais, rituais e simbólicas que são partilhadas pela sociedade envolvida. É por se acomodarem mal às estruturas presentes numa determinada sociedade que as epidemias se tornam lócus privilegiado para o exame de diferentes dimensões da vida social, dos elementos que organizam e dão sentido à experiência cotidiana de indivíduos e grupos.

Este texto enfoca algumas experiências epidêmicas vivenciadas pela população de Minas Gerais (Brasil) ocorridas especialmente durante a segunda metade do século XIX. Através dele buscamos observar alguns aspectos convergentes entre essas experiências e algumas proposições apresentadas pela historiografia das epidemias. Privilegiando duas moléstias específicas, a varíola e o cólera, concentramos nossa abordagem sobre a atuação dos poderes públicos durante o período imperial brasileiro (1822-1889), enfatizando seus limites no enfrentamento de episódios dessa natureza, e sobre a mobilização social em torno da resolução dos problemas colocados pelas experiências epidêmicas.

\section{As epidemias na província de Minas Gerais}

As doenças contagiosas foram presença constante nas terras mineiras durante todo o período provincial ${ }^{3}$. Malária, diarréias, sífilis, morféia, hepatite, pneumonia, coqueluche, tuberculose, varíola, catapora, sarampo e uma ampla gama de febres ${ }^{4}$ - tifóide, terçãs, intermitentes, perniciosas, inflamatórias, intestinais - são freqüentemente assinaladas pelas autoridades. A intensidade e os impactos dessas moléstias variavam enormemente:

3. No período imperial brasileiro (1822-1889) o termo «Província» era usado para referir-se às unidades administrativas regionais. Em grande medida, as províncias deram continuidade às unidades territoriais prevalentes na época colonial —as «Capitanias»— sendo transformadas em «Estados» no período republicano. Gouvêa, Maria de Fátima S. Províncias. In: Vainfas, Ronaldo, dir. Dicionário do Brasil Imperial (1822-1889). Rio de Janeiro: Objetiva; 2002, p. 597-599.

4. A febre, hoje entendida como sintoma de diferentes moléstias, foi, até bem avançado o século XIX, considerada uma enfermidade, assumindo formas diversas e originando o que se acreditava serem moléstias distintas. 
algumas vezes apresentavam-se de forma branda, fazendo poucas vítimas; em outras, eram vistas como verdadeiro flagelo, enfermando significativo número de pessoas e matando varias delas. Foi o que ocorreu em Rio Pardo no ano de 1869, quando a cidade foi assaltada por uma epidemia de febres intermitentes e malignas «com tal intensidade, que no espaço de três meses era raro o dia em que não fosse sepultada uma vítima» 5 .

Entre os diversos eventos epidêmicos que assolaram a província de Minas Gerais durante o século XIX, nenhum foi tão persistente e alcançou tanta proeminência como a varíola ${ }^{6}$. Um levantamento nos relatórios apresentados pelos presidentes da província à Assembléia Legislativa, entre 1837-1889, sugere não haver praticamente um ano no qual a população não tenha convivido com a presença da doença:

«De todas as epidemias que costumam nos afligir, a da varíola é a que mais estragos faz, não só pela própria gravidade, como ainda mais pelo terror que infunde na população. Infelizmente temos todos os anos povoações invadidas por este mal, que nos vem da Corte ${ }^{7}$, ou de outros lugares da Província de São Paulo, onde ela reina quase endemicamente» ${ }^{8}$.

As consultas dirigidas pelo Governo Provincial às Câmaras Municipais interrogando sobre o estado sanitário e a presença de epidemias em cidades e povoados, freqüentemente eram respondidas com menções à varíola. Como as demais doenças epidêmicas, essas manifestações da varíola podiam apresentar um caráter benigno, com um número reduzido de contaminados; em outros momentos, a doença assumia uma feição terrível, ceifando a vida de considerável quantidade de vítimas. Algumas vezes, a propagação da varíola - benigna ou não- ficava circunscrita a certas vilas

5. Correspondência recebida (Saúde e assistência), Arquivo Público Mineiro, Belo Horizonte, referenciado nas notas seguintes como APM. Fundo Presidência da Província, SP.PP., 26, cX. 02, doc. 11. 25.

6. A varíola foi também uma das principais ameaças à saúde pública no Brasil durante o período imperial, como revelam Chalhoub, Sidney. Cidade febril: cortiços e epidemias na Corte Imperial. São Paulo: Companhia das Letras; 1996, e Fernandes, Tânia M. Vacina antivariólica: ciência técnica e o poder dos homens, 1808-1920. Rio de Janeiro: Fiocruz; 1999.

7. O termo «Corte» faz referência à cidade do Rio de Janeiro, município neutro, sede política do regime imperial e residência oficial da família real brasileira. Abreu, Marta. Corte. In: Vainfas, n. 3, p. 175-177.

8. Relatório que à Assembléia Provincial de Minas Gerais apresentou no ato da abertura da Seção Ordinária de 1865, o Desembargador Pedro de Alcântara Cerqueira Leite, Presidente da mesma Província. Ouro Preto: Tipografia do Minas Gerais; 1865, p. 34. 
ou povoados, mas houve ocasiões em que a doença expandiu-se por várias localidades da província num curto espaço de tempo, instaurando o medo entre a população e também entre as autoridades.

Ocorrência dessa natureza foi observada entre 1873-1875, quando diversos municípios mineiros foram atacados pelo que parece ter sido uma manifestação mais virulenta da moléstia ${ }^{9}$. A constante referência a presença da varíola em distintas localidades da província torna difícil precisar a origem desse recrudescimento da doença, porém, a documentação oficial aponta que, naquele momento, a varíola havia assumido uma natureza mais grave, ampliando significativamente o espectro de seu contágio e a mortalidade a ela atribuída.

Os relatos sobre esse episódio apontam que, a 15 de setembro de 1873, o Chefe de Polícia de Ouro Preto, então capital da província, informava às autoridades provinciais a presença entre os integrantes do Corpo Policial de um soldado infectado com a varíola ${ }^{10}$. Tão logo identificada a doença, o Inspetor de Saúde Pública Provincial solicitou sua remoção para o Jardim Botânico - local que em outras ocasiões havia funcionado como lazareto provisório-, uma vez localizar-se nos arrabaldes da cidade. Apesar dessa medida, a doença acabou invadindo a capital. Nos meses de outubro e novembro a epidemia grassou em Ouro Preto, porém, «sem tomar proporções assustadoras» ${ }^{11}$. Conforme declarações do presidente da província, em função do declínio observado no mês de dezembro e das opiniões de profissionais autorizados, acreditou-se que a moléstia desapareceria breve-

9. Segundo Alfred Crosby, a virologia reconhece dois tipos de varíola: a varíola major, que apresentava uma alta taxa de mortalidade, de cerca de 25 a 30\% (que provavelmente corresponderia ao se chamava no Brasil de «bexigas» bravas) e a varíola minor, que apresentava sintomas mais brandos e taxa de mortalidade de $1 \%$ ou menos. As características da virose certamente variavam durante os séculos, considerando-se também muito provável a existência de cepas de virulência intermediária. Crosby, Alfred W. Smallpox. In: Kiple, Kenneth F., ed. The Cambridge world history of human disease. Cambridge: Cambridge University Press; 1993, p. 1008-1013. A imunidade temporária promovida pela vacina, a baixa adesão à prática e as dificuldades encontradas na montagem de um serviço eficaz (resultando num diminuto número de imunizados) talvez também possam contribuir para a compreensão de algumas manifestações mais disseminadas da doença.

10. Carta da Secretaria de Polícia em Ouro Preto, 15 de Set de 1873. APM, Belo Horizonte Fundo Secretaria de Governo. SG. 584 (Correspondência recebida pela Presidência da Província referente à saúde pública).

11. Relatório que à Assembléia Legislativa Provincial de Minas Gerais apresentou no ato de abertura da Seção Ordinária de 1874 o Vice-Presidente Francisco Leite da Costa Belém. Ouro Preto: Tipografia de J. F. de Paula Castro; 1874, p. 31. 
mente. Entretanto, três meses depois a doença havia recrudescido, atingindo maior intensidade em junho de 1874, quando matou 37 pessoas. A varíola ainda permaneceria na capital até o início de março de 1875, totalizando 789 infectados 204 mortos $^{12}$.

Além de Ouro Preto, a epidemia de 1873-1875 também foi observada em outras localidades da província. Correspondência encaminhada pela Câmara de Aiuruoca informava que a varíola havia invadido o povoado de Alagôa. Segundo o documento, as bexigas ${ }^{13}$ apresentaram-se com um «caráter maligno (...) sendo tão bravas que pessoas que já tinham tido ainda foram acometidas, porém com caráter benigno» ${ }^{14}$, e mesmo aqueles que haviam sido vacinados também contraíram a doença. Na cidade de Juiz de Fora a moléstia perdurou de setembro de 1873 a fevereiro do ano seguinte, infectando cerca de 1000 pessoas e fazendo 135 falecidos, num total de 241 vítimas inumadas naqueles meses no cemitério público ${ }^{15}$.

Significativo número de óbitos foi ainda registrado em Carmo da Cachoeira, freguesia da cidade de Lavras, onde a Câmara estimava 200 vítimas, considerada uma «mortalidade espantosa em tão pequena população» ${ }^{16}$. O impacto da doença também foi expressivo no povoado do Inficcionado, município de Mariana, onde, numa população pouco superior a 300 indivíduos, 125 foram infectados, dos quais 20 faleceram ${ }^{17}$. Ao final da epidemia, o município de Mariana contou 537 infectados e 161 mortos $^{18}$. Entre os 71 municípios que integravam a província de Minas Gerais naquele período,

12. Relatório que o Ilm. e Exm. Sr Dr Francisco Leite da Costa Belém, 2 Vice-Presidente da Província de Minas Gerais apresentou, no ato de passar-Ihe a Administração da mesma Província, ao Exm Sr Desembargador João Antônio de Araújo Freitas Henriques, a 6 de março de 1875. Ouro Preto: Tipografia de J. F. de Paula Castro; 1875, p. 12.

13. O termo «bexiga(s)» era usado no Brasil como sinônimo de varíola desde a época colonial. Santos Filho, Lycurgo. Pequena história da medicina brasileira. São Paulo: Editora Parma; 1980, p. 45.

14. Correspondência, n. 5, cx. 03, doc. 19.

15. Correspondência, n. 5, cx. 04, doc. 13. A título de comparação, foram sepultados no mesmo cemitério no período mencionado, 39 vitimas de febres («quase todas de thipho»). Dos 66 óbitos restantes, as causas se distribuíam entre outras 12 moléstias distintas, além de parto, velhice, desastres.

16. Relatório, n. 11, p. 32. Para uma população de cerca de 5.410 pessoas, segundo dados divulgados em 1874 relativos ao recenseamento realizado pela Diretoria Geral de Estatística do Império entre os anos de 1872 a 1874. Relatório, n. 11, p. 74.

17. Relatório, n. 11, p. 31.

18. Relatório, n. 12, p. 12. 
cerca de 31 informaram a presença da epidemia de varíola ao Inspetor de Saúde Provincial ${ }^{19}$.

Menos abrangente, mas igualmente impactante, foi a manifestação do cólera nos anos de 1855-1856. A doença ficara especialmente conhecida pelos horrores que produzia nos grandes centros urbanos europeus na primeira metade do século XIX. O terror alimentado em relação ao cólera era explicado não só pela alto índice de mortalidade entre os infectados - cerca de 50\% - mas também pela rapidez e a forma degradante pela qual a morte sobrevinha ${ }^{20}$. Acresce-se a isso as medidas sanitárias - quarentenas e reformas urbanas-impostas pelas autoridades que causavam tanto medo quanto a própria doença.

A chegada do cólera e sua expansão por diversas províncias do Império causaram apreensão no governo mineiro. Em fins de 1855, documento enviado pela administração provincial às Câmaras de todos os municípios indicava a necessidade de precaver-se contra a invasão da moléstia. Para tanto encaminhava um impresso com algumas instruções elaboradas pela Junta Central de Higiene do Império, instituía uma comissão sanitária em cada cidade, destinava a quantia de 2:000\$000 ${ }^{21}$ para o atendimento à pobreza desvalida e insistia na importância da mobilização das comunidades em torno da caridade e da filantropia para fazer frente ao flagelo iminente da moléstia. A correspondência trocada entre as autoridades locais e o Governo Provincial aponta que poucas foram as cidades atingidas pelo cólera naquele período - Ubá, Leopoldina, Baependi, Cristina e Barbacena- e com um número de vítimas comparativamente menor em relação ao que se verificou em outras regiões do Império ou em relação à epidemia de varíola mencionada acima. Entretanto, a ameaça da moléstia não deixou de mobilizar grande parte das autoridades, além de atemorizar a sociedade ${ }^{22}$.

19. Correspondência recebida pela Presidência da Província referente à saúde pública. APM, Belo Horizonte, Fundo Secretaria do Governo. SG. 259, doc. 257.

20. Evans, Richard J. Death in Hamburg: society and politics in the cholera years 1830-1910. London: Penguin Books; 1987, e Rosenberg, Charles E. The cholera years: The United States in 1832, 1849 and 1866. Chicago: The University of Chicago Press; 1987.

21. Durante o período Imperial, a unidade monetária vigente no país era o mil réis: $1 \$ 000$. Mil unidades de réis era equivalente ao conto de réis, ou apenas conto: 1:000\$000. Carreira, Liberato C. História financeira e orçamentária do Império do Brasil. 2 vols. Brasília: Senado Federal; 1980.

22. Relatório que á Assembléia Legislativa Provincial de Minas Gerais apresentou na abertura da sessão ordinária de 1857 o conselheiro Herculano Ferreira Penna, presidente da mesma província. Ouro Preto, Tipografia. Provincial, 1857, p. 24. 


\section{O Estado e a assistência em tempos de epidemia}

A atuação das autoridades durante estes dois episódios não fugiu à regra observada em outros eventos epidêmicos que assolaram a província no correr do século XIX. Entre as medidas postas em prática para fazer frente à varíola na cidade de Ouro Preto estavam: a nomeação de uma comissão sanitária composta pelo Presidente da Câmara Municipal, o Inspetor de Saúde Pública da Província, dr. Carlos Thomas de Magalhães Gomes e o cirurgião-mor de brigada dr. Manoel de Araújo Gesteira, então responsável pela administração do lazareto do Jardim Botânico. Também foi instalada na rua das Cabeças, próximo ao lazareto, uma «casa de convalescença» para onde foram transferidos os doentes em recuperação oriundos daquele hospital.

A fim de evitar uma maior expansão do mal, foram proibidos enterramentos no interior das igrejas. Esses deveriam ser feitos em caixões fechados e em covas com «a conveniente profundidade» (de cerca de 10 palmos, conforme as posturas recentemente estabelecidas pela Câmara da cidade). A condução dos infectados, dos mortos e a remoção de colchões e roupas dos falecidos pela varíola, ficaram a cargo do Chefe de Polícia, que para esse serviço contratou oito indivíduos, de forma a evitar que «praças e galés» ${ }^{23}$ propagassem o mal para a cadeia e o quartel ${ }^{24}$. Determinou-se ainda que o transporte de doentes e mortos seria feito pela rua do Xavier, resguardando-se as ruas de maior trânsito, de modo a evitar o contágio. As necessidades dos doentes recolhidos ao lazareto -como medicamentos, dietas, camas e demais utensilios- eram supridas pela Santa Casa de Misericórdia. Os soldados e presos pobres, cujo atendimento era atribuição do governo, também eram tratados no mesmo estabelecimento ${ }^{25}$.

23. O termo «praça» era comumente usado para designar militares ou soldados não graduados, e "galés» refere-se aos presos condenados a trabalhos forçados. Dicionário Houaiss de Língua Portuguesa. Rio de Janeiro: Objetiva; 2001, p. 1417, 2275.

24. Cópia de correspondência expedida pela Presidência da Província referente à saúde pública, 13/06/1874. APM, Belo Horizonte, Fundo Secretaria do Governo. SG. 528, p. 52.

25. Durante o século XIX o atendimento aos policiais e militares estaria a cargo de enfermarias e hospitais militares mantidos pelo governo. Na primeira metade do século, havia três hospitais militares, dois dos quais remanescentes do período colonial: dos Dragões do Governo de Minas Gerais, em Ouro Preto, e do Contrato Diamantino, na cidade do Serro. Há referências a um hospital militar em Sabará, a propósito do qual, no ano de 1843, indicava-se a extinção, visto o pequeno número de doentes e as despesas de manutenção. Sugeria-se que os militares fossem atendidos pela Santa Casa existente naquela cidade. Medida parecida seria tomada 
Segundo relatório do Vice-Presidente da província, Francisco Leite da Costa Belém, o Governo foi sempre solícito em tomar as necessárias providências para combater a epidemia ${ }^{26}$. Porém, fazendo uma avaliação das ações postas em prática pelas autoridades provinciais durante essa incursão da varíola, o Inspetor de Saúde afirmava que, tais providências iam sendo tomadas «à proporção que sua necessidade foi aparecendo», e que, apesar de necessárias, eram «infelizmente bem pouco eficazes quando o mal já havia infectado toda a cidade $(. ..){ }^{27}$. Com raras exceções - como na invasão no país pelo cólera em 1855-1856, em que houve a determinação de vigilância de fronteiras e a desinfecção de todas as roupas, caixas, cangalhas e o mais necessário em poder daqueles que procediam de áreas que haviam relatado a «infecção» pela moléstia ${ }^{28}$-, é possível afirmar que, durante o século XIX, o governo provincial normalmente começava a agir somente quando essas enfermidades já haviam se instalado.

Mesmo quando as autoridades buscavam antecipar-se à invasão de uma moléstia contagiosa, essa atuação foi, em muitas ocasiões, essencialmente reativa, uma vez que visava impedir a expansão e não a invasão de determinado lugar pela moléstia ${ }^{29}$. Exemplo disso é observado em 1887, quando o então Inspetor de Higiene, Manoel de Aragão Gesteira, indicava as seguintes medidas «preventivas» diante de uma nova ameaça da varíola

em relação no atendimento das praças do corpo policial e dos soldados de linha da capital mineira e, em 1871, o governo também transferia o atendimento dos presos internados na enfermaria da cadeia pública à Santa Casa de Misericórdia de Ouro Preto, que ficava responsável pelo fornecimento de dietas e medicamentos mediante uma diária de 1 \$200 por cada um. Salles, Pedro. História da Medicina no Brasil. 2a ed., Belo Horizonte: Coopemed; 2004 e Relatório que apresentou ao Exm. Sr. Vice-Presidente da Província de Minas Gerais, Dr. Francisco Leite da Costa Belém, por ocasião de Ihe passar a Administração em 20 de abril de 1872, o Dr. Joaquim Pires Machado Portela, Presidente da mesma Província. 1872, p. 18 (ms). APM, Belo Horizonte.

26. Relatório, n. 11, p. 32.

27. Correspondência recebida pela Presidência da Província referente à saúde pública, Ofício de 9 de novembro de 1874, APM, Belo Horizonte, Fundo Secretaria do Governo. SG. 529.

28. Ainda por ocasião dessa epidemia de cólera, as autoridades remeteram às câmaras um extrato dos conselhos da Comissão Central de Saúde Pública (preceitos gerais de higiene e terapêutica) instalada no Rio de Janeiro, e nomeavam uma comissão sanitária em cada um dos municípios, dispondo a quantia de 2:000\$000 para a assistência da classe indigente. Ofícios e mais papéis dirigidos ao governo sobre a saúde pública, APM, Belo Horizonte, Fundo Secretaria do Governo Provincial, SP. 574, docs. 233, 313, 358, e Ofícios e mais papéis dirigidos ao governo sobre a saúde pública e casas de caridade SP. 600, doc. 139.

29. Engberg, Elisabeth. A influenza invisível: a resposta comunitária à pandemia de 1918-1920 no norte rural da Suécia. Vária História. 2009; 25 (42): 429-456. 
à capital: desocupação e caiação do prédio do Jardim Botânico, ficando o mesmo à disposição da Santa Casa; autorização para que a mesa da Santa Casa adquirisse 20 leitos completos e duas redes com colchas; disponibilização à Presidência da Câmara de novas «correntes de galés» (com a competente força para escoltá-los) para ocuparem-se na limpeza das ruas e becos da cidade; continuar a abertura da estrada do Morro do Raimundo até o caminho do Jardim Botânico; recomendar atenção ao comandante do corpo policial com os soldados provenientes de lugares infectados pela moléstia $^{30}$. E, no caso de invasão da doença restaria, como de costume, prover o socorro à pobreza desvalida, com o auxílio de um médico para tratá-los e de um padre para confessá- $\operatorname{los}^{31}$.

Sobre os recursos disponibilizados pelo poder público por ocasião desses eventos, os dados levantados para o período provincial permitem inferir que estes raramente foram capazes de impedir a instalação destas moléstias, ou mesmo suficientes para satisfazer as necessidades por elas impostas. Carta dirigida pela cidade de Mar de Espanha à Secretaria de Governo, em 1855, apontava a exigüidade dos 2:000\$000 para assistir aos pobres dos sete distritos que integravam o município no caso de invasão do cólera ${ }^{32}$. Durante a epidemia de varíola em 1873-1875, a Presidência da Província abriu três créditos no valor de 1:600\$000 para a Câmara de Juiz de Fora, que havia contado o maior número de infectados. Na capital foi gasto um total de pouco mais de 11:000\$000. Os créditos liberados para a maioria dos outros municípios variaram entre $200 \$ 000$ a 1:500\$000. Havia, porém, algumas cidades atacadas pela moléstia, para as quais não se fez referência a nenhum auxílio específico. Ao fim da epidemia, o crédito total disponibilizado pelas autoridades provinciais alcançou o valor pouco inferior a 22:600:000, sendo a despesa efetivamente realizada da ordem de $16: 690 \$ 000^{33}$.

30. Correspondência recebida pela Presidência da Província referente a saúde pública. Carta da Inspetoria de Higiene, 22 de Ago de 1887. APM, Belo Horizonte, Fundo Secretaria do Governo. SG. 533.

31. Originais, ofícios e... APM, Belo Horizonte. Fundo Secretaria do Governo Provincial, SP. 574, doc. 130.

32. Originais, n. 31 , doc. 358 .

33. Relatório, n. 12, p. 13. A título de comparação, no balanço apresentado pela tesouraria provincial sobre o período de 1873-1874, consta o gasto de 358:348\$048 com a instrução primária e secundária. Ver no mesmo Relatório: Apenso n. ${ }^{4}$. Relatório da Inspetoria da Tesouraria Provincial de Minas, p. 16. 
Durante os eventos epidêmicos, a atuação das Câmaras na organização da assistência à população seguia as mesmas diretrizes anteriormente mencionadas para a capital da província: instituição de uma comissão responsável pelo atendimento aos doentes, composta na maioria das vezes pelo vigário, um médico e um boticário ou, na ausência destes últimos, pelos chamados «entendidos» ${ }^{34}$; aquisição de medicamentos nas boticas existentes com os créditos recebidos, ou, na falta destas, mandados buscar em outras cidades; instalação de lazaretos para o isolamento dos infectados. Tais medidas certamente não foram observadas em todas as localidades atingidas pela doença, pois, tanto quanto as rendas, também era escasso o pessoal qualificado. Freqüentemente as autoridades reconheciam estar a população à mercê de curiosos e ignorantes, ou da natureza e da providência divina, uma vez não haver «alma» que velasse pelos enfermos em significativo número dos povoados e vilarejos do interior de Minas Gerais ${ }^{35}$. Se, em ocasiões de epidemia, o governo designava um médico para prestar os socorros necessários nessas localidades, suprindo os pobres com remédios e dietas, cessada a ameaça a população voltava a conviver com a desassistência e o desamparo por parte do Estado.

Os recursos e socorros dispensados pelo poder público visavam a chamada classe indigente, a qual faltavam os meios para garantir a própria subsistência. Até mesmo os poucos hospitais existentes na província durante o período, tinham como sua maior clientela as pessoas miseráveis. Essas instituições compunham-se majoritariamente das casas de caridade, alcunhadas «asilo da pobreza». Ainda que freqüentemente contassem com a subvenção de verbas públicas, a criação e manutenção de estabelecimentos que velassem pela saúde dos desvalidos era iniciativa que cabia aos moradores e às Câmaras Municipais. Não seria exagero dizer que, excluindo-se a salubridade pública e o socorro aos pobres, a saúde no século XIX foi essencialmente uma questão privada.

34. Leigos com algum esclarecimento ou possuidores de noções rudimentares nações das artes de curar. Santos, n. 13, p. 40-41.

35. Em 1846, por exemplo, a Câmara de Barbacena afirmava avultar no município os charlatães, «pela maior parte tão ignorantes, que sem saber a própria língua, vão manipulando suas boticas irregulares, e logo que tem de cor um certo número de receitas [estréiam] a sua carreira ceifando quantas vítimas Ihes caem nas mãos». Fala dirigida á Assembléia Legislativa Provincial de Minas Gerais na Sessão Ordinária do ano de 1846, pelo Presidente da Província, Quintiliano José da Silva. Ouro Preto: Tipografia Imparcial de B.X. Pinto de Sousa; 1846, p. 35. 
Se o período imperial brasileiro é caracterizado pela historiografia como momento de crescente restrição à autonomia municipal e a conseqüente concentração do poder pelo governo central $^{36}$, no âmbito da saúde esse movimento não é claramente observado. No ano de 1828 as atribuições relativas à saúde pública -desempenhadas pela Real Junta do Protomedicato até 1808 e depois pelos físico-mor e cirurgião-mor e seus comissários provinciais - foram transmitidas para as Câmaras Municipais. Entre as funções das Câmaras constavam: a elaboração das posturas policiais, que englobavam questões relativas ao exercício profissional, higiene pública e assistência, cuidando ainda para $\mathrm{o}$ «estabelecimento e conservação das casas de caridade para a criação dos expostos e a cura dos doentes necessitados» ${ }^{37}$. Cada cidade deveria contar com um Médico ou Cirurgião do Partido da Câmara, a quem seria delegada a assistência aos pobres, assim como aos presos que se encontrassem doentes. A autonomia das Câmaras nas questões relacionadas à saúde foi reafirmada em outras decisões do Império, que apontavam não terem os presidentes de província qualquer ingerência nas posturas das câmaras, sujeitas apenas a aprovação dos Conselhos Gerais ${ }^{38}$.

A Junta de Higiene Pública, criada em 1850 - a partir de 1851, Junta Central de Higiene Pública - apontada por alguns estudiosos como medida centralizadora no âmbito da saúde, tinha sua atuação praticamente circunscrita à Corte. Nas províncias, foi criado no mesmo período o cargo de Provedor de Saúde Pública —em dezembro de 1857, Inspetor de Saúde Pública - que deveria empenhar-se na investigação das causas da insalubridade das localidades, observar o curso das moléstias reinantes, e empregar toda a vigilância sobre qualquer tema relacionado à saúde da população - como a fiscalização do exercício da medicina, boticários e droguistas-, ou o regulamento dos cemitérios ${ }^{39}$. Entretanto, a existência dessa legislação e de órgãos e cargos criados na esfera da administração pública não permitem pressupor uma efetiva atuação das diferentes instâncias de

36. Alencastro, Luiz Felipe de. A vida privada e a ordem privada no Império. In: Novais, Fernando, org. História da vida privada no Brasil: Império. São Paulo: Companhia das Letras; 1997, vol. 2, p. 17.

37. Lei de $1{ }^{\circ}$ de outubro de 1828. Coleção de Leis do Brasil de 1809. Rio de Janeiro: Imprensa Oficial; 1878, p. 74-89.

38. Coleção de decisões do Governo do Império do Brasil de 1831. Rio de Janeiro: Tipografia Nacional; 1876, p. 190.

39. Decreto n. 598 de 14 de setembro de 1850. Coleção de Leis do Império do Brasil de 1850. Rio de Janeiro: Tipografia Nacional; s/d, p. 299-301. 
poder no cumprimento da lei ou de suas atribuições. Considerando-se as informações oficiais levantadas para Minas Gerais sobre esse período, é possível afirmar que nem as leis nem as autoridades tinham a abrangência, a eficiência e a articulação necessárias para a solução dos problemas de saúde, e que a própria percepção sobre esses problemas e suas soluções era bastante estreita ${ }^{40}$.

A pesquisa documental tem sugerido que a intenção de centralização das ações relacionadas à saúde, expressa na reorganização dos serviços e na criação da Junta de Higiene Pública, acabaria resumindo-se mais ao estabelecimento de diretrizes que deveriam ser observadas pelos governos provinciais e locais. Os estudos sobre a saúde no período imperial têm revelado que, aquilo que informava a lei não refletia a experiência cotidiana da população. Se havia o interesse de expansão do controle e da uniformização de práticas relativas à saúde no período imperial, havia também dificuldades de toda ordem limitando sua consecução: a fragilidade da estrutura burocrática; a descontinuidade das ações; a desarticulação entre as diferentes esferas administrativas (central, regional e local) intervindo negativamente na organização e gerenciamento da assistência; a ausência de ações conjuntas entre províncias distintas; os recursos reduzidos disponibilizados pela administração imperial; a deficiência de rendas da maioria das câmaras, impedindo o cumprimento das determinações relativas à assistência à saúde; e mesmo as próprias percepções em torno da saúde/ doença, associadas a teorias atmosféricas, sobrenaturais, ou marcadas por uma abordagem moralista ou caritativa. Reafirmando o que sugere a historiografia que tematiza outras questões da administração pública imperial, é possível dizer que, no âmbito da saúde o Estado também encontrava grandes obstáculos na tentativa de estender sua «hegemonia» a todo o território imperial $^{41}$.

40. Em relatório do ano de 1837, o presidente da província afirmava: «A ilustração, o emprego do tempo em trabalhos úteis, a propagação da vacina, e as Casas de Caridades, parece-me que serão os meios mais apropriados para conservar-se a saúde pública, prolongar-se a existência, e aumentar progressivamente a população». Fala dirigida à Assembléia Legislativa Provincial de Minas Gerais na Sessão Ordinária do ano de 1837 pelo Presidente da Província, Antônio da Costa Pinto. Ouro-Preto: Tipografia do Universal; 1837, p. XV.

41. Dolhnikoff, Miriam. O pacto imperial: origens do federalismo no Brasil. São Paulo: Globo; 2005, p. 85 . 


\section{Caridade e assistência em tempos de epidemia}

A fragilidade do poder público em cumprir uma agenda de saúde efetiva era frequêntemente compensada pela caridade e a filantropia. No correr do século XIX foram diversas as ocasiões nas quais a mobilização social desincumbiu-se das atribuições que eram facultadas ao governo. E não seria erro dizer que, para o Estado, a oferta de serviços de saúde não prescindia dessa mobilização social. A principal forma de organização da assistência caritativa à saúde no Brasil até o final do século XIX foi a Irmandade da Misericórdia ${ }^{42}$. O modelo assistencial das Misericórdias foi herança portuguesa organizada por volta de $1498^{43}$, e transposta para seu vasto império colonial. Entre as 14 obras de caridade que integravam o compromisso da Irmandade, estava a assistência aos desvalidos, em especial aos enfermos e, diversamente de outras confrarias presentes no império português, a Irmandade da Santa Casa da Misericórdia privilegiava a assistência aos outros cidadãos, e não apenas aos seus próprios confrades ${ }^{44}$. Para além das ações caritativas, as Misericórdias funcionavam como espaço de organização e reprodução da sociabilidade e da desigualdade durante o Antigo Regime português, assim como um mecanismo capaz de garantir às elites acesso ã administração dos negócios públicos, assim como seu comprometimento no atendimento das demandas populares em torno de diversas formas de assistência social ${ }^{45}$.

Apesar da independência política conquistada e 1822, muitas das estratégias de administração e de organização da vida pública durante o império português permaneceram período imperial brasileiro. Um exemplo dessa permanência pode ser observada através da Lei n. ${ }^{\circ} 148$, sancionada em 6 de abril de 1839, e que autorizava a criação de um hospital de caridade em todas as cidades e vilas que ainda não contassem com tal benefício.

42. Sanglard, Gisele. A construção dos espaços de cura no Brasil: entre a caridade e a medicalização. Revista Esboços. 2006; 16: 11-33.

43. Nesse ano foi criada em Lisboa, sob a direção da rainha D. Leonor, a confraria dedicada a Nossa Senhora da Misericórdia, reformando e centralizando as diversas formas de assistência caritativas existentes desde o período medieval. Russell-Wood, A. J. Fidalgos e Filantropos: A Santa Casa de Misericórdia da Bahia, 1550-1755. Brasília: Ed. Universidade de Brasília; 1981.

44. Abreu, Laurinda. O papel das Misericórdias dos «lugares de além-mar» na formação do Império português. História, Ciências, Saúde. 2001; 8 (3): 591-611 (599).

45. Quiroga, Ana Maria. Assistência e poder: revendo uma articulação histórica. Praia Vermelha. 2008; 18 (1): 14-28. 
Seu texto informava que as câmaras deveriam promover subscrições entre os habitantes para a compra do edifício e o para o fundo das despesas dos mesmos, convidando-os ainda a prestarem uma anuidade a favor dos estabelecimentos. A décima parte deste valor deveria ser empregada na compra de apólices da dívida pública, que seriam incorporadas aos bens da instituição. À mesa diretora - composta pelos doadores das maiores quantias - cabia a edificação e administração, devendo ainda, nomear «comissões, que nas paróquias, e curatos promovam os interesses dos mesmos hospitais, solicitando e arrecadando as esmolas e quaisquer donativos que lhes forem oferecidos» ${ }^{46}$.

Durante o século XIX, são recorrentes as recomendações para que as câmaras providenciassem a abertura de subscrições entre a população para o socorro dos desvalidos, seja em tempos de normalidade ou sob as ameaças epidêmicas. Em certos momentos, o recurso ao «humanitarismo» precedia o recurso ao Estado, como revela correspondência enviada ao governo provincial em reposta a uma circular encaminhada por ocasião da epidemia de cólera de 1855-1856, determinando que «deverão interceder a favor dos indigentes a caridade e a filantropia das pessoas abastadas»e, quando esses recursos da caridade pública e os da câmara não fossem suficientes, ficaria a mesma autorizada a fornecer medicamentos adquiridos com a verba disponibilizada pela Coletoria Provincial ${ }^{47}$.

O alcance dessa mobilização pode ser visto em São João Del Rei, onde a câmara informava a criação de comissões de bairros para promover a subscrição em favor da classe indigente. Também oficiou aos boticários a autorização para o aviamento, por crédito da mesma, de quaisquer receitas dos médicos da comissão sanitária, que trouxesse a indicação "pobre colérico». Fixou a gratificação de $12 \$ 000$ diários ao médico que prestasse seus serviços no lazareto que pretendia instalar. Para isso, já havia autorizado o arrendamento de uma casa, tendo a Mesa Administrativa da Santa Casa se comprometido a oferecer camas, roupas e outros «misteres» necessários. E, na dificuldade em se arrendar a casa pretendida, era autorizada a disposição do edifício da Câmara para o mesmo fim. Além disso, também eram expedidas ordens tratando do asseio e limpeza da cidade ${ }^{48}$.

\footnotetext{
46. Coleção Leis Mineiras. 1839, p. 89. APM, Belo Horizonte.

47. Originais, n. 31, doc. 262. Ver ainda, SP. 574, doc. 210, doc. 229.

48. Originais, n. 31, doc. 146 e 147.
} 
Se em tempos normais a assistência hospitalar era iniciativa que cabia aos moradores e às Câmaras Municipais - valendo-se de subscrições e esmolas inclusive para a manutenção de seus serviços- em tempos de epidemia a situação não seria diferente. Na maior parte das localidades da província de Minas Gerais a instalação de lazaretos e hospitais para o atendimento aos enfermos coléricos só ocorreu por causa da mobilização dos moradores, que ofereciam dinheiro, imóveis, utensílios e o pessoal necessário para fazer frente às emergências impostas pela invasão dessas moléstias $^{49}$. Da vila de Baependi, o delegado de polícia informava haver um hospital já estabelecido e mais duas casas destinadas ao mesmo fim, contando todos eles com os respectivos médicos responsáveis ${ }^{50}$. Em São José da Paraíba, além de 2:000\$000 oferecidos por dois moradores, uma subscrição foi organizada entre os habitantes visando a montagem de um lazareto para o recolhimento dos doentes. O autor da correspondência dizia ainda empregarem-se todos os esforços «a fim de que se desenvolva o espírito de caridade, tão necessário nessas épocas calamitosas», confiando no patriotismo de seus conterrâneos ${ }^{51}$.

A mobilização social orquestrada contra os impactos das epidemias é observada ainda em carta do Presidente da Câmara da Vila de Cristina durante a epidemia de cólera de 1855-1856, na qual apontava haver uma moradora da cidade destinado quatro escravas para ajudarem no atendimento prestado aos enfermos no hospital ali instalado. Outro morador oferecia seus cativos e animais para buscar nas cidades vizinhas os medicamentos e outros produtos que se fizessem necessários ${ }^{52}$. Outros documentos apontavam a presença de estudantes do curso médico, às vezes hospedados na residência de algum benemérito, prestando seus auxílios no atendimento aos doentes coléricos da cidade. Muitos médicos, além de disporem-se a integrar as comissões sanitárias encarregadas do combate a moléstia, também ofereciam quantias em espécie para o socorro aos indigentes, comprometendo-se, alguns deles, no atendimento gratuito aos infectados pelo cólera ${ }^{53}$.

\footnotetext{
49. Originais, n. 31, doc. 447.

50. Originais, ofícios e ... APM, Belo Horizonte. Fundo Secretaria do Governo Provincial, SP. 600, doc. 130.

51. Originais, n. 31, doc. 405

52. Originais, n. 50, doc. 178 .

53. Originais, n. 31 , doc. 125
} 
Prática presumida por parte daqueles que apresentavam uma situação social mais confortável, a caridade foi também uma atitude entre aqueles a quem esperava-se que ela socorresse - revestida aqui do caráter do cristão piedoso. Em fevereiro de 1874, a comissão sanitária responsável pelo combate à varíola em Ouro Preto informava que até mesmo alguns pobres contribuíam com o fornecimento de caixões e outros meios de auxílio para o enterramento das vítimas da doença. Em fins de 1855, o pároco da cidade de Jacuí exortava a todos os fiéis «para que recíproca e mutuamente usem da caridade» a fim de minorar os sofrimentos impostos pelo cólera ${ }^{54}$.

\section{Da compaixão à intolerância e de algumas práticas para se ver livre da ameaça epidêmica}

Se os impasses impostos pelas epidemias propiciavam sentimentos de compaixão, também levavam à intolerância. O temor imposto pelo contágio se traduzia em desconfiança e discriminação, especialmente em relação àqueles julgados responsáveis pela invasão do mal. Em Santa Luzia do Carangola, o aparecimento da varíola em pessoa residente em uma fazenda, fez serem imediatamente expulsos do lugar alguns mendigos que há muito tempo viviam no local ${ }^{55}$. O medo da acusação e da exclusão eram outros elementos constituintes da explicação sobre o receio que o povo denotava à vacina, como revela uma comunicação da Câmara de São Romão apontando que quase ninguém queria sacrificar-se a ser o primeiro a submeter-se aquela prática em função dos «justos receios» de que o pus inoculado pudesse degenerar-se em bexigas bravas, o que provocaria a «conspiração do povo em geral contra o doente de tal contágio ${ }^{56}$. Temendo a instalação da casa para os convalescentes da varíola, os moradores da rua das Cabeças, em Ouro Preto, realizaram um abaixo assinado em oposição à medida, afirmando que, apesar de ser positiva para os doentes, a iniciativa era "prejudicialíssima» para os habitantes do lugar, «visto ser este o estágio no qual o contágio

\footnotetext{
54. Originais, n. 31, doc. 430.

55. Correspondência recebida pela Presidência da Província referente à saúde pública. Carta de Santa Luzia do Carangola, 28/09/1887. APM, Belo Horizonte. Fundo Secretaria do Governo, SG. 533.

56. Correspondência, n. 5, cx. 3, doc. 06.17.03.
} 
se opera mais facilmente» ${ }^{57}$. A medida os forçaria a se retirarem de suas residências, sendo por isso considerada uma violação de seus direitos. Vale mencionar que, antes que a escolha recaísse sobre o edifício em questão, outros proprietários se recusaram a ceder seus imóveis para esse fim.

$\mathrm{O}$ medo à doença e aos doentes, também era expresso na fuga dos lugares infectados. No povoado do Inficcionado, cerca de 50 pessoas (1/6 dos habitantes) deixaram a localidade para evitar a varíola durante a epidemia de 1873-1874. O temor do contágio também instalou-se entre a população de Arassuaí no ano de 1878, em função da presença da varíola no vizinho arraial de Itinga:

«reina a maior consternação e o pânico é tal, que num só dia mais de 300 pessoas abandonaram seus lares, espavoridas e aterradas à presença da medonha moléstia, de cuja invasão se acha ameaçada esta cidade pela proximidade em que está daquela localidade, notando-se já grande tormenta nos espíritos» ${ }^{58}$.

Foi também o temor à varíola que afastou os deputados da capital mineira, impedindo a reunião da Assembléia Provincial no ano de $1874^{59}$. Esse medo ainda distanciava as pessoas, prejudicando a oferta dos cuidados necessários à recuperação. Escrevendo às autoridades provinciais sobre uma incursão da varíola verificada em Santa Luzia do Carongola em 1887, cuja mortalidade havia alcançado cerca de $50 \%$ dos que haviam sido infectados, o médico responsável pelo lazareto informava que mais da metade da população havia fugido da cidade, transformando o lugar numa verdadeira necrópole. Os que ficaram tinham tanto horror em sair de suas casas que três deles acabaram sendo encontrados mortos no interior das mesmas ${ }^{60}$.

Enquanto alguns fugiam, outros evitavam a qualquer custo o contato com as áreas nas quais essas terríveis moléstias se manifestavam. Em sua representação ao governo provincial contra a instalação da «casa de convalescentes», os moradores da rua das Cabeças, lembravam ser o lugar um dos pontos de entrada de inúmeras tropas que abasteciam a capital de Mi-

57. Correspondência recebida pela Presidência da Província referente à saúde pública. APM, Belo Horizonte. Fundo Secretaria do Governo, SG. 529, doc. 172.

58. Correspondência n. 5, cx. 06, doc. 42.

59. Relatório, n. 11, p. 3.

60. Correspondência recebida pela Presidência da Província referente à saúde pública, Carta de Santa Luzia do Carangola, 28/09/1887. APM, Belo Horizonte. Fundo Secretaria de Governo. SG. 533. 
nas, podendo a presença dos doentes afugentá-las, gerando conseqüências danosas para toda a cidade. O problema da oferta de gêneros, «que nas crises epidêmicas tornam-se escassos e encarecem consideravelmente» ${ }^{61}$, era preocupação recorrente daquela sociedade. Apesar da proximidade com áreas atacadas pelo cólera no Rio de Janeiro, o presidente da Câmara de Leopoldina afirmava não haver ainda caso da doença na cidade, destacando porém, achar-se a população «aterrada e possuída de um pânico assustador, (...) [estando por isso] paradas todas as tropas, todo o comércio paralisado» ${ }^{62}$. No ano de 1859 , os boatos de que a cidade de Ouro Preto encontrava-se tomada pelas bexigas, fizeram recrudescer a carestia de gêneros. Para afastar o flagelo da fome, o governo viu-se obrigado a publicar desmentidos sobre a epidemia e enviar carta aos fazendeiros das redondezas, de modo a demover o temor dos comerciantes. A fim de coibir os atravessadores, comprou víveres «para o rancho da cadeia e ainda para socorrer à pobreza (...) [evitando] que a fome pesasse com todos os seus horrores sobre a gente mais necessitada ${ }^{63}$.

Além da preocupação com o abastecimento, esses eventos confrontavam a sociedade com uma série de outras deficiências cotidianas. Para todo o século XIX, a documentação evidencia o quanto eram limitados os recursos materiais no âmbito da saúde investidos no território de Minas de Gerais ${ }^{64}$. Além dos escassos hospitais, faltavam profissionais habilitados para o tratamento dos enfermos. A penúria vivida pela população fez muitas vezes sobrepor-se a satisfação das necessidades à observância das leis, não sendo raras as solicitações de manutenção de práticos e boticas, ainda que desprovidos das respectivas licenças, nas cidades e povoados. A instalação de uma epidemia com seu séquito de doentes avultava ainda mais tais deficiências, como revela informe do Presidente da Câmara da cidade de Cristina, durante a epidemia de cólera de 1855-1856: «J́ vamos sentindo a falta de medicamentos e médicos, já que os dois práticos que existem são

\footnotetext{
61. Originais, n. 31, doc. 65 e 66 .

62. Originais, n. 31, doc. 131.

63. Relatório que o IIm. e Exm. Sr Dr Joaquim Delfino Ribeiro da Luz, 1 Vice-Presidente da Província entregou ao $\mathrm{Ilm}$. Sr. Conselheiro Carlos Carneiro de Campos em o dia 6 de abril de 1859 no momento de seguir para a Vila de Lavras a fim de assistir às arrematações da Estrada do Passa Vinte. Ouro Preto: Tip. Provincial, 1859, p. 59.

64. Silveira, Anny J T e Marques, Rita de Cássia. A saúde e o estado na província de Minas Gerais. In: Resende, Maria Efigênia L, org. Província de Minas Gerais. Belo Horizonte: Companhia do Tempo/ Autêntica; 2010 (no prelo).
} 
poucos a acudirem aos doentes» ${ }^{65}$. Em vista da ausência de médicos e da extensão do município, o dr. João das Chagas Andrade, responsável pela organização dos socorros aos coléricos na cidade de Oliveira, solicitava ao Governo Provincial autorização para que alguns práticos e curiosos pudessem auxiliá-lo naqueles encargos ${ }^{66}$.

Por outro lado, a preocupação constantemente manifestada pelas autoridades com a presença de charlatães e curadores - «inclusive os de feitiço» ${ }^{67}$ - que ministravam tratamentos indevidos (como cachaça com gengibre para os doentes do cólera), ou com os indivíduos que sem habilitação legal andavam pelos distritos a inocular o pus pestífero, apontam que a população recorria a diferentes promessas de proteção e cura, muitas vezes mais próximas, tanto materialmente quanto culturalmente, de suas crenças e percepções do que as práticas oficialmente chanceladas. A chamada variolização ${ }^{68}$ parecia ser uma prática difundida, como mostra informação do comissário vacinador municipal de Piranga, durante a manifestação da doença no ano de 1871. Segundo ele, o cidadão João José Roiz havia retirado as crostas de bexigas de um «enxertado», usando-a depois em uma "crioulinha» e "daí procedeu-se todo o contágio, do qual foram vitimas três indivíduos» ${ }^{69}$. A mesma associação era feita, em 1874 , pelo exInspetor de Saúde Provincial, dr. Eugênio Domingos Nogueira, apontando que o incremento da epidemia na povoação do Inficcionado «foi devido a inoculação do vírus variólico, que geralmente se faz no povo» ${ }^{70}$.

No caso da varíola, é interessante notar que, apesar das constantes referências à indiferença da população à vacina, são também recorrentes na documentação as solicitações da linfa vacínica pelas autoridades das localidades invadidas pela moléstia, dizendo que muitos buscavam a vacina exatamente quando do aparecimento das bexigas. Durante a epidemia de 1873-1874, o comissário vacinador de Juiz de Fora apontava que o número de pessoas que o procuravam diariamente era tão grande que «apenas restavame transmitir a vacina, não me restando tempo para fazer assentamento»,

\footnotetext{
65. Originais, n. 50, doc. 166 e 167.

66. Originais, n. 31, doc. 167.

67. Correspondência n. 5, cx. 03, doc. 05.19.

68. Prática que consistia na remoção de material das pústulas ou de crostas de doentes e sua inoculação em pessoas sãs e que, segundo os estudiosos do tema, remontava ao primeiro milênio da era cristã. Chalhoub, n. 6, p. 102-105.

69. Correspondência, n. 5, cx. 03, doc. 05.16.

70. Correspondência, n. 5, cx. 04, doc. 03.
} 
calculado por ele cerca de 1.400 vacinados ${ }^{71}$. Essa posição, que confrontada com o temor gerado pela vacina parece contraditória e irracional, ganha lógica quando pensada no interior da crise epidêmica: afinal, o principal objetivo nesses momentos era a sobrevivência, independente dos meios utilizados. Qualquer sugestão que prometesse a cura ou a proteção do flagelo era bem vinda, independente do lugar de sua produção.

Apesar das poucas menções encontradas na documentação, acreditamos não ser absurdo supor que durante eventos dessa natureza a população recorresse a um variado arsenal de produtos, que compunham o que poderíamos chamar uma farmacopéia popular ou uma farmácia caseira. O mesmo pode ser dito em relação às práticas místicas, com o apelo à intercessão divina. Sobre essas há um relato trágico, vindo do povoado de São Miguel, cidade de Santa Bárbara. Durante a epidemia de cólera de 1855-1856, realizouse naquele vilarejo uma procissão com a «venerada» imagem do Senhor Bom Jesus de Matozinhos. Reunindo uma «multidão» de cerca de quatro mil pessoas, a manifestação visava aplacar a ira de deus e aliviar a nação do flagelo da epidemia reinante. Porém, enquanto o cortejo atravessava as águas do rio que cortava a localidade, parte da ponte veio abaixo, lançando à correnteza mais de trezentas pessoas. «Sabe-se por hora de duas mulheres mortas, mais de oitenta feridos, e destes mais de vinte gravemente, que é provável sucumbirem ${ }^{72}$. Assim como se observou durante os eventos epidêmicos, nesse inesperado acidente os socorros foram prestados pela própria população, e não tendo a câmara recursos para satisfazer de pronto as necessidades, os órfãos e feridos ficaram a cargo da caridade pública.

\section{Considerações}

Ainda que a varíola constituísse uma experiência relativamente freqüente na sociedade mineira do século XIX, as aparições da moléstia em sua forma epidêmica não deixaram de causar espanto e alterar o curso da vida cotidiana de diversas localidades da província. Do mesmo modo, e ainda que fosse uma doença nova nessas paragens, a irrupção do cólera também instalou o pânico, causando impacto entre aquela população pela influência

71. Correspondência, n. 5, cx. 04, doc.13.

72. Originais, , n. 31, doc. 257. 
das notícias sobre o flagelo provocado pela moléstia em outras regiões do Império, como também, do histórico de outras experiências epidêmicas, acompanhadas de todas as suas conseqüências, então vivenciadas pela população da província.

O caráter amplamente difuso dessas doenças, atacando a um só tempo considerável número de pessoas, faz das manifestações epidêmicas eventos que freqüentemente ultrapassam a capacidade de atuação das autoridades no provimento das necessidades relativas à saúde pública. No caso de Minas Gerais, é possível dizer que as epidemias, ao ampliarem significativamente o número de doentes que recorriam à assistência pública, tinham um impacto importante sobre os serviços de saúde então disponíveis. Entretanto, também é possível perceber que as dificuldades vivenciadas quando da instalação do cólera ou do recrudescimento da varíola, na verdade evidenciavam e aprofundavam as deficiências que perduravam em tempos de normalidade. Por outro lado, o grau de abandono ao qual algumas localidades estiveram constantemente condenadas permite dizer que foi somente durante algum evento epidêmico que suas populações tiveram acesso a algum tipo de assistência -o socorro médico, o acesso a medicamentos, a possibilidade de matar a fome. Cessada, entretanto, a doença, eram novamente relegadas à penúria e ao desamparo.

A incapacidade revelada pelas autoridades públicas em prover as necessidades da população em momentos epidêmicos foi freqüentemente compensada pela mobilização da própria sociedade. Mesmo vivendo sob as pressões impostas pela doença é possível identificar um amplo movimento visando socorrer os infelizes atingidos tanto pela varíola como pelo cólera na província durante o século XIX. Por outro lado, considerando a forma como era concebida a assistência à saúde durante o período, podemos dizer que aquela mobilização não era de todo uma novidade. Como se viu, a saúde era em grande medida tratada como assunto privado, um encargo da caridade e da filantropia. Em relação a esse tema, podemos pensar ainda que o engajamento das pessoas no socorro aos seus semelhantes nesses tempos de calamidade podia expressar diferentes coisas: um sentimento puramente humanitário, um cálculo racional na busca pela sobrevivência e pela restauração da ordem, a necessidade de afirmar e confirmar - ou o desejo de conquistar- um status no seio da sociedade.

As manifestações da compaixão social, tantas vezes exacerbada quando confrontadas com uma calamidade epidêmica, são amiúde acompanhadas por sentimentos menos nobres. O medo inspirado por essas doenças tam- 
bém promove reações de exclusão, de abandono, de preconceito. Desse modo, essas experiências podem ser consideradas contraditoriamente como o tempo da solidariedade e o tempo da solidão. O reconhecimento da existência de reações tão díspares pode ser justificado pela afirmação do evento epidêmico como um tempo de contrastes e de extremos. Mas também podemos imaginar que esse evento apenas ilumina, ou expõe a complexidade e o caráter contraditório da própria existência humana, muitas vezes matizado pelas necessidades impostas pela própria vida em sociedade. 
